\title{
Reassessing the empirical relationship between the oil price and the dollar
}

Virginie Coudert \& Valérie Mignon

\section{Highlights}

- Changes in the real price of oil and the U.S. dollar real effective exchange rate are linked by a negative relationship over the 1974-2015 period, while the link is positive over the subsample ending in the mid2000s.

- We estimate a nonlinear, smooth transition regression model in which the oil price-dollar nexus depends on the dynamics followed by the U.S. currency.

- We show that the relationship is negative most of the times but turns positive when the dollar hits very high values, as in the early eighties. 


\section{Abstract}

This paper aims at reassessing the empirical relationship between the real price of oil and the U.S. dollar real effective exchange rate over the 1974-2015 period. We find that changes in both variables are now linked by a negative relationship, going from the dollar exchange rate to the real oil price. However, the same relationship is found positive when ending the sample in the mid-2000s, in line with the previous literature. To understand and investigate this evolution, we rely on a nonlinear, smooth transition regression model in which the oil price-dollar nexus depends on the dynamics followed by the U.S. currency. Our results show that the relationship is negative most of the times but turns positive when the dollar hits very high values, as in the early eighties.

\section{Keywords}

Oil price, Dollar real effective exchange rate, Causality, Nonlinearity.

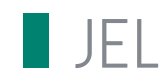

C22, F31, Q43.

\section{Working Paper}

\section{CEPII}

CEPII (Centre d'Etudes Prospectives et d'Informations Internationales) is a French institute dedicated to producing independent, policyoriented economic research helpful to understand the international economic environment and challenges in the areas of trade policy, competitiveness, macroeconomics, international finance and growth.
CEPII Working Paper

Contributing to research in international economics

(c) CEPII, PARIS, 2015

All rights reserved. Opinions expressed in this publication are those of the author(s) alone.

$\begin{array}{ll}\text { Editorial Director: } & \text { CEPII } \\ \text { Sébastien Jean } & \text { 113, rue de Grenelle } \\ & 75007 \text { Paris } \\ \text { Production: } & +33153685500 \\ \text { Laure Boivin } & \\ \text { No ISSN: } 1293-2574 & \text { Prw.cepii.fr }\end{array}$




\title{
Reassessing the empirical relationship between the oil price and the dollar*
}

\author{
Virginie Coudert $^{*}$ and Valérie Mignon ${ }^{* *}$
}

\section{Introduction}

A number of key economic variables exhibit large fluctuations that contribute to the global economic cycle. The two most important of them are certainly the oil price and the dollar stance. A decline in the oil price is able to boost domestic demand in all oil-consuming countries by cutting their energy bill, whereas dollar appreciation is likely to improve their external trade by enhancing export competitiveness. The combination of both factors is hence often considered as a good omen for global growth, although not always sufficient to sustain activity by its own.

Given the importance of oil in the global economy and since the U.S. dollar is the key currency on the oil market, the question of the potential links between the price of oil and the U.S. dollar exchange rate is crucial. This question has become even more acute with the recent sharp fluctuations observed on both the oil and U.S. forex markets. Indeed, the oil price has been falling since June 2014 , while the U.S. currency has exhibited an appreciating trend. One key issue is then to determine if this evolution in opposite direction is a typical feature regarding historical records.

As a matter of fact, the real oil price and the U.S. dollar real effective exchange rate (REER) have regularly displayed large fluctuations since the seventies. However, these swings evolve over time, being sometimes parallel, and at other times in opposition, as shown in Figure $1 \mathrm{~A}$. Hence if there exists a relationship between the oil price and the dollar, it is not a linear one. For instance, in the early 1980s, both variables upsurge, leading to a positive relationship. On the contrary, at the end of the period, since the mid-2000s, they exhibit a scissor-movement, typical of a negative relationship. The current situation characterized by an appreciating dollar and a decreasing oil price falls within this latter context. Besides, the correlation between the change in real oil price and the USD real exchange rate also exhibits strong evolution over the last decades (Figure 1B). Whereas it was quite unstable from 1974

\footnotetext{
- Corresponding author: Valérie Mignon, EconomiX-CNRS, University of Paris Ouest, 200 avenue de la République, 92001 Nanterre Cedex, France. Phone : 331409758 60. Email: valerie.mignon@uparis10.fr.

Bank of France, EconomiX-CNRS, University of Paris Ouest and CEPII. Email: virginie.coudert@banque-france.fr.

${ }^{*}$ EconomiX-CNRS, University of Paris Ouest and CEPII. Email: valerie.mignon@u-paris10.fr.
} 
to 2005 but on average slightly positive at $0.11 \%$, the correlation coefficient turned strongly negative, reaching $-55.37 \%$ on average from January 2006 until August 2015 (the end of our period under study). This evolution towards high negative correlation is also evidenced on daily data by Fratzscher et al. (2014).

A key issue concerns the direction of the relationship between the two variables. As highlighted by Coudert et al. (2007) among others, this is not clear cut and if a causality exists, its direction is not unequivocal. Indeed, the theoretical considerations point to various transmission channels between the oil price and the dollar, that lead to different signs and directions of the relationship (see Section 2). This issue is particularly relevant in the recent context in which the appreciating dollar resulting from the anticipated exit from the quantitative easing policy in the U.S. tends to put prices under pressure, making oil investments less attractive for investors. The main question remains to know whether this conjunction of factors-strong dollar and low oil price-is a mere coincidence. Investigating the interactions between the oil price and the dollar is thus a key concern, which is precisely the aim of the present paper.

Figure 1. Real oil price and U.S. real effective exchange rate

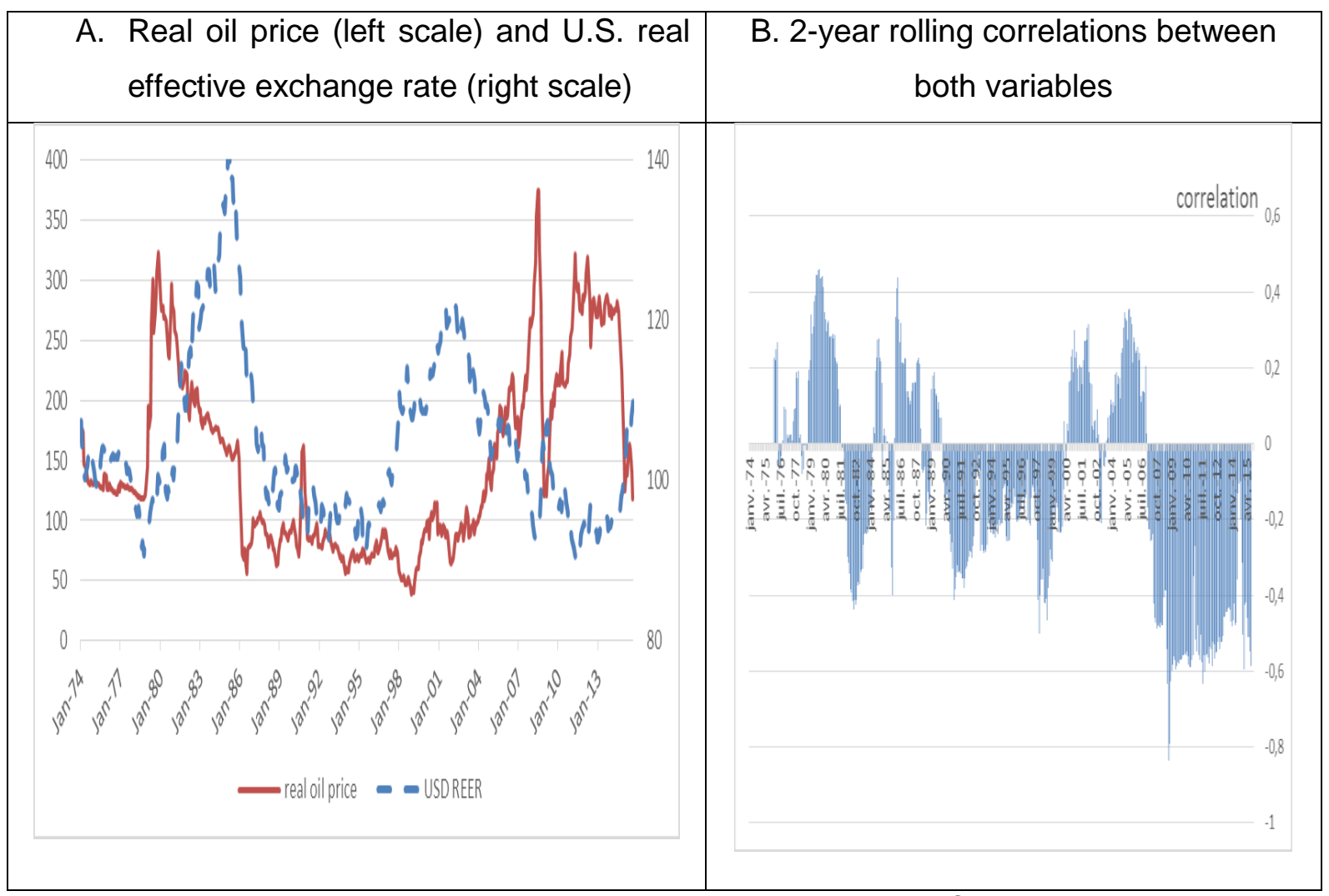

Note: data are monthly and expressed as indexes based 100 in 1990. Correlations are calculated on the monthly change in the logarithm of the two variables. See Section 3 for data sources 
To disentangle the alternative theoretical explanations, we rely on an empirical analysis over the January 1974-August 2015 period, and investigate both the long-run and short-run links between the real oil price and U.S. dollar real effective exchange rate on a monthly basis. While the existing literature mainly relies on linear specifications, our main contribution is to account for the equivocal sign of the relationship between the two variables by considering the framework of nonlinear, smooth transition regression models. The nonlinear formulation allows us to account for the changes of signs in correlations between the two variables observed over the last decades. Such specification is particularly attractive for our purpose, since the nexus between the oil price and the dollar can be assessed differently according to the situation on the foreign exchange market.

The rest of the paper is organized as follows. Section 2 describes the theoretical links between the dollar exchange rate and the oil price. Section 3 presents the data and the results of some preliminary tests. Section 4 displays the results linked to the estimation of our nonlinear specifications. Section 5 concludes the paper.

\section{The theoretical links between the two variables}

There are a number of reasons why the dollar and the oil price should move together, either positively or negatively. However, most of these rationales point to a negative relationship. Let us list all these reasons below and classify them according to the direction of the implied relationship.

\subsection{Oil demand and supply effects of a change in the USD}

As oil price is denominated in U.S. dollar, fluctuations in the dollar exchange rate directly affect the oil price for non U.S. countries, which triggers demand and supply effects for the petroleum products. Regarding the demand side, a dollar appreciation makes oil more expensive for countries whose currencies are not pegged to the U.S. dollar, while the effect is neutral for the U.S. as well as for USD-peggers like China. On average, everything else being equal, a dollar appreciation tends to cut real income in consumer countries, dampening their demand for oil. Consequently, through this slowing effect on demand, a dollar appreciation contributes to decreasing the oil price. Turning to the supply side, a dollar appreciation tends to damp down inflation and increase purchasing power in oil-producing countries, improving their real disposable income and, in particular, the income available for drilling, everything else being equal. Overall, the dollar appreciation effect on oil supply is positive. To sum up, a stronger dollar tends to dampen demand and boost supply for oil, both 
effects resulting in a declining oil price. Therefore, these demand and supply effects entail a negative relationship, with a causality that runs from the U.S. dollar to the oil price.

\subsection{Petrodollars recycling and second-round trade effects}

With reference to the works of Krugman (1983a, 1983b) and Golub (1983), a reverse causality can be at play. These authors investigate the effects of wealth transfers following an oil price shock by using portfolios models and a schematic decomposition of the world into three main areas-the United States, the European Union (or Germany) and OPEC. The links between the oil price and the U.S. dollar exchange rate are described through trade and portfolio interactions between the three zones in the aftermath of a change in the oil price. According to Golub (1983), an oil price hike tends to strengthen the dollar (relatively to the euro) as OPEC's propensity to hold dollars is relatively high. Indeed, the appetite of oilexporting countries for depositing their assets in dollars entails a positive link between the two variables. Overall, higher oil prices feed larger demand for USD assets through petrodollars recycling, which strengthened the dollar rate. As shown, the relationship between the two variables is positive, with a causality running from the oil price to the U.S. dollar. However, this effect can be mitigated when considering the second-round effects for trade. If the U.S. exports proportionally less goods to OPEC than the European Union, then the U.S. will benefit less from the surplus of demand in OPEC countries following an oil price rise. This distortion in trade is able to generate a dollar depreciation (Krugman, 1983a, 1983b). To sum up, following an oil price hike, the petro-dollar recycling effects are likely to make the dollar appreciate, as long as OPEC countries are willing to hold USD assets, while second-round trade effects will push the dollar down, as OPEC countries buy most of their goods out of the U.S.

\subsection{Oil price and the equilibrium exchange rates}

The causality from the oil price to the exchange rate may also be apprehended through the literature on equilibrium exchange rates, which relates long-run movements in the real exchange rates to economic fundamentals (Clark and McDonald, 1998; Faruqee, 1995). Few economic fundamental factors have been identified as able to drive the real exchange rate on the long run, and most studies point to only three significant variables: the BalassaSamuelson effect (difference in relative productivity between tradable and non-tradable sectors), the net foreign assets and the terms of trade (see e.g. Coudert et al., 2011). Strikingly, because of the key position of oil in international trade, the oil price is able to drive important changes in both the latter factors. Let us first consider the effects running through the net foreign assets. If they accumulate in a given country, the country's currency can 
appreciate without impeding its current-account balance, as capital income takes over the loss in trade receipts induced by the deteriorated competitiveness. As the oil price has large impacts on all countries' trade balances, it is also determinant to the building-up of external assets that in turn affects the exchange rates in the long run. Indeed, when the oil price surges, petroleum exporters hoard more external assets, leading their real exchange rate to appreciate. Things go the other way round for oil-importing countries that get impoverished, which results in less foreign assets and a depreciating currency. Turning to the terms of trade, the oil market also plays a key role. Higher oil price matches better terms of trade for oil exporters, that make their currency appreciate without adverse consequences on their trade account; on the contrary, fuel-importers have to depreciate their currency to cope with their deteriorated terms of trade. Consequently, following an oil price hike, both terms of trade and external assets produce the same effects on the exchange rates: appreciating the currencies of fuel-exporters and depreciating those of net importers.

These mechanisms apply to all currencies, although their effects can be attenuated for the USD due to its unique position as the key reserve currency in the international monetary system. Actually, the persistent trade deficits in the U.S. have regularly undermined the country's net foreign assets that have become more and more negative since the mideighties. This situation has contributed to weaken the equilibrium exchange rate of the U.S. dollar (see for example Cline, 2011), although its actual fall has been prevented by its reserve currency status. More than anything, a large fraction of the U.S. trade deficit is due to the petroleum products. The recent improvement in the U.S. trade account, along with the anticipated rise of interest rates through the tapering policy, may explain the dollar strength since the beginning of 2014. The narrowing trade deficit itself has several causes, among which the sharp drop in crude oil prices since 2014, although the substantial cuts in imports through dampening internal demand also play a large role in the aftermath of the financial crisis. Overall, through these mechanisms, a lower (higher) oil price causes the USD real exchange rate to appreciate (depreciate), which implies a negative relationship between the two variables.

\subsection{The financialization of the commodity market}

Financial factors may also play a role in the relationship between the oil price and the dollar. Since the mid-2000s, the tremendous development of commodity futures has introduced new possibilities of arbitrage between financial assets, commodity contracts and forex markets (Domanski and Heath, 2007). Asset managers, banks, hedge funds and specialized traders, are increasingly active in these markets (Greely and Currie, 2008; Mayer, 2009). Commodity futures have been more and more used by these financial operators to diversify their 
portfolios, especially during bear stock markets. As oil is predominant among commodity contracts, this evolution concerns oil in the first place. Some authors consider that commodity futures can be viewed as a hedge against losses occurred on the U.S. stocks and bonds (Gorton and Rouwenhorst, 2006; Kat and Oomen, 2006), while others directly point to oil futures as alternative investments in a diversified portfolio (Geman and Kharoubi, 2008).

In this perspective, a fall in the price of U.S. assets and the USD itself can easily lead asset managers to move towards commodities, bidding up their prices. Therefore, the financialization process of the commodity market may have resulted in a negative relationship running from the USD exchange rate to the oil price.

\subsection{Possible responses to common factors in the global economy}

As both the dollar rate and the oil market are closely linked to the overall stance of the global economy, indirect channels can be at work to explain co-movements between these two variables. The most likely one goes through the U.S. monetary stance. A rise in the U.S. interest rate-whether actual or just anticipated like in 2014 and 2015-typically lifts the dollar rate, through the uncovered interest rate parity; but it could also bring about an anticipated slowdown in the world economy, that could mitigate demand for oil. In this context, a restrictive shock in the U.S. monetary policy could generate both a higher dollar and a lower price of oil, the reverse being true with an expansive stance. Such an indirect channel may also explain negative correlations between the oil price and the USD. Other factors such as global financial crises, stock crashes, peaks in risk aversion or episodes of high volatility on stock markets may also distort exchange rates as well as impact the price of oil.

To sum up, most mechanisms at stake point to a negative relationship between the oil price and the dollar: whether it be through oil demand and supply responding to a dollar hike, the equilibrium exchange rate of the dollar adjusting to deteriorating foreign assets following an oil price rise, or the financialization process allowing asset managers to arbitrage between U.S. assets and oil futures. Even the possible indirect channels through interest rates and risk aversion also lead to negative interactions. The only positive channel is found through petrodollar recycling, leading wealthier oil-exporters to bid up dollar assets in the aftermath of an upsurge in oil prices. 


\section{Data and preliminary tests}

\subsection{Data}

We consider monthly data covering the period from January 1974 to August $2015 .{ }^{1}$ The crude oil price series is defined as the average of U.K. Brent, Dubai \& West Texas Intermediate prices, extracted from Macrobond. It is expressed in real terms, using the U.S. consumer price index as the deflator (source: Macrobond). The exchange rate is the U.S. dollar real effective exchange rate, extracted from the OECD database (Main Economic Indicators). ${ }^{2}$

\subsection{Questioning the existence of a long-term relationship between the oil price and the dollar}

Some previous empirical studies have investigated the relationship between exchange rates and the oil price, such as Throop (1993), Zhou (1995), Amano and van Norden (1995), Dibooglu (1995), Bénassy-Quéré et al. (2007), Coudert et al. (2007) and Fratzscher et al. (2014). Regarding the issue of causality between the two variables, Amano and van Norden (1995) have shown that oil price is the main driving factor of the long-term evolution of exchange rates in Germany, Japan and the United States. Bénassy-Quéré et al. (2007) and Coudert et al. (2007) obtained a positive relationship over the 1974-2004 period for the U.S. case. However, as shown by Figure 1, this positive link between the oil price and the dollar seems to have greatly evolved over the last decade. The existence of a long-term, cointegrating relationship between both variables seems now unlikely once the series have been updated with the post 2005 period. Indeed, Fratzscher et al. (2014) showed that the correlations between oil price and the USD exchange rate have turned negative since the early 2000s, whereas being positive beforehand.

To address this issue and to bring updated conclusions regarding the oil price-dollar nexus, we first test for the existence of a cointegrating relationship. Using the Johansen (1988)'s methodology, our results show that the null hypothesis of no cointegration between the real price of oil and the USD REER cannot be rejected at the $5 \%$ significance level. ${ }^{3}$ This

\footnotetext{
${ }^{1}$ Our analysis starts in 1974 since this date corresponds to the beginning of the floating exchange rate period, avoiding the turbulences of the 1973 transition year.

${ }^{2}$ It should be noticed that our aim being to focus on the bivariate link between the dollar and the price of oil, we do not include economic fundamentals in our estimated relationships. However, for the sake of completeness, additional variables have been considered in our VAR estimations (see Section 3.3), confirming the direct interactions between our two variables of interest and illustrating the robustness of our results.

${ }^{3}$ Complete results of unit root and cointegration tests are available upon request to the authors. In short, the unit root tests lead us to conclude that the two series are integrated of order 1 , the null
} 
conclusion confirms the graphical intuition provided by Figure 1 showing that the relationship between the two variables became unstable, turning negative over the last decade.

\subsection{Short-run dynamics and causality}

To investigate the direct interactions between the oil price and the dollar, we proceed to the estimation of a bivariate VAR process in differences. Figure 2 summarizes the main results by displaying the corresponding generalized impulse responses functions. As shown, an oil price shock does not impact the dollar, whereas a dollar appreciation has a significant negative impact on the oil price on the short run.

As these results could stem from a simultaneous reaction to a missing variable in the model, we check for indirect interactions. As the U.S. monetary stance is the most likely indirect channel playing a role on both variables, we incorporate the Federal Funds rate (taken from the Fed database) into the VAR. The impulse response functions of the trivariate VAR show that the U.S. interest rate hike triggers a significant appreciation of the dollar, as expected through the uncovered interest parity but has no significant direct impact on the oil price (see Figure A1 in Appendix). More importantly, in the trivariate VAR, a dollar appreciation still exerts a negative significant impact on the oil price, while the reverse is not true. Therefore, introducing a third variable in the model does not change the interactions between our two variables of interest, as the impact of the U.S. interest rate on the oil price goes only through the dollar exchange rate. These results therefore give support to our previous findings obtained through the bivariate VAR, suggesting direct interactions between the oil price and the dollar.

hypothesis of no cointegration not being rejected at the $5 \%$ significance level using both the trace and maximum eigenvalue tests. 
Figure 2. Generalized impulse-response functions

Response to Generalized One S.D. Innovations \pm 2 S.E.

Response of D(LREER) to D(LREER)

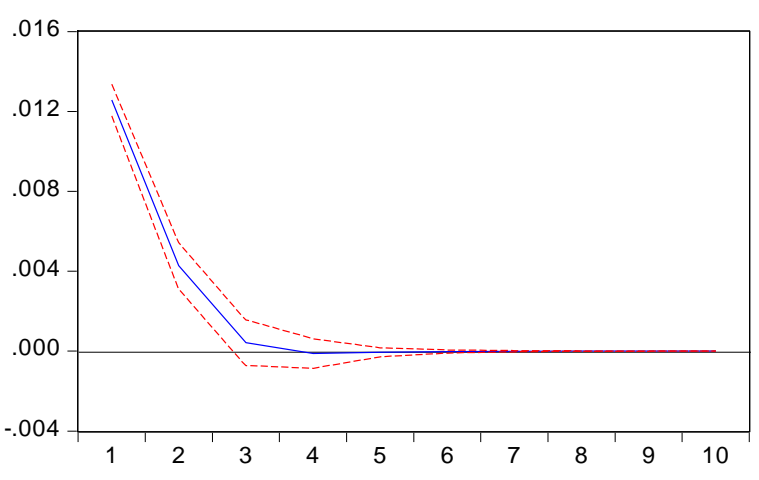

Response of $\mathrm{D}$ (LOIL) to $\mathrm{D}($ LREER)

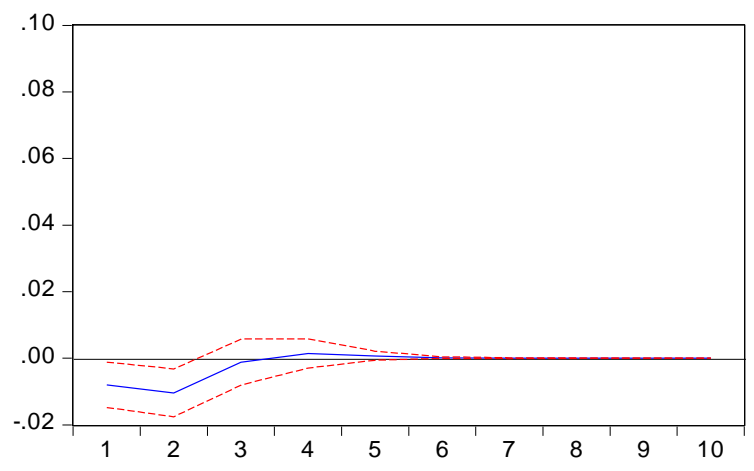

Response of $\mathrm{D}(\mathrm{LREER})$ to $\mathrm{D}(\mathrm{LOIL})$

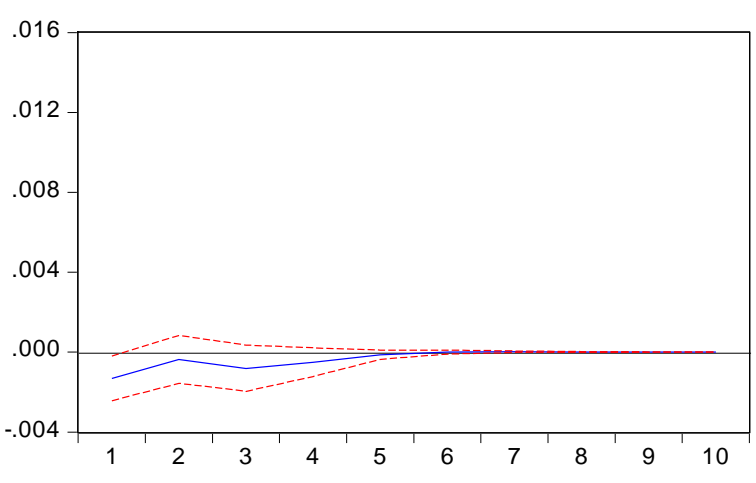

Response of $\mathrm{D}$ (LOIL) to $\mathrm{D}(\mathrm{LOIL})$

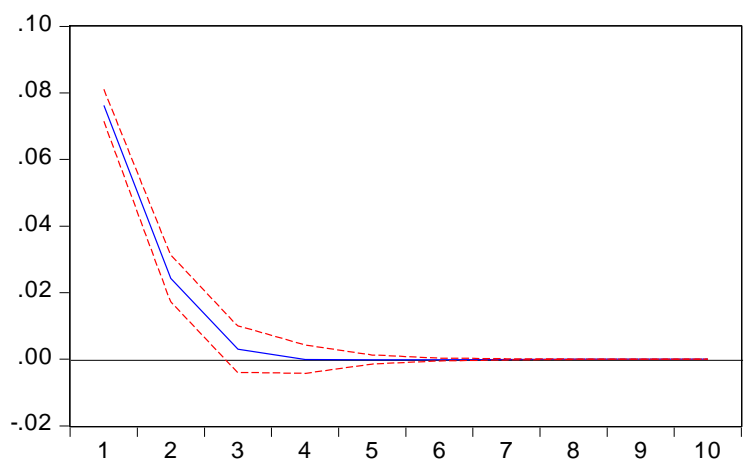

Note: the generalized impulse-response functions correspond to the estimation of a VAR(2) process in first differences. The lag of the VAR process has been selected using information criteria.

As financial crises may also impact our two variables of interest, especially on our period including the 2008 year, we proceed to another check by introducing a proxy of financial stress in the former bivariate VAR. To this end, we retain the volatility of the U.S. stock market, as number of studies has shown that the VIX is a good gauge for financial stress (see for example Becker et al., 2009). As the VIX is not available at the start of our period, we take the U.S. stock market index from the OECD database and calculate its monthly realized volatility as a rolling standard deviation on a two-year window. According to our results, ${ }^{4}$ financial stress has no significant impact neither on the dollar nor on the oil price. However, as previously, the inclusion of this third variable does not change our findings obtained from the bivariate VAR: the oil price responds significantly and negatively to the dollar REER, while the reverse does not hold.

\footnotetext{
${ }^{4}$ Results are not given for the sake of brevity but are available from the authors.
} 
To complement this preliminary analysis, we proceed to the application of the Granger causality test over two periods: the whole period from February 1974 to August 2015, and the earlier period beginning at the same time but ending in July $2004 .{ }^{5}$ The oil price does not cause the dollar neither over the whole period nor the shorter one. On the contrary, the reverse causality is evidenced, running from the real effective exchange rate to the real price of oil. The results show that the causality relation has strengthened (as the p-value decreases from $9.75 \%$ to $4.54 \%$ ) since the earlier period, but has also changed sign, as the positive relationship has turned negative over the whole period.

This conclusion is particularly interesting as it highlights an important change in the relationship between both variables since the mid-2000s. It is related to our previous arguments on the financialization of the oil market that has taken place since the early 2000s. Correlations between oil price and the dollar rate have turned more and more negative as arbitrage between commodity futures and USD assets has been facilitated by the growing size of the market. Moreover, since the beginning of the 2000s, as the U.S. current-account deficit reached record levels able to threaten the dollar value, the OPEC countries have become more and more willing to diversify their portfolios out of the U.S. and buy assets all across the world. This new OPEC's financial strategy implemented mainly through their sovereign wealth funds has weakened the traditional "petrodollar recycling" effect that used to link the oil price and the dollar rate positively. Turning to the recent situation, our analysis tends to indicate that the dollar appreciation has pulled down the price of oil.

\footnotetext{
${ }^{5}$ We retain this date as it corresponds to the end of the period investigated in various previous studies (see, e.g., Bénassy-Quéré et al., 2007 and Coudert et al., 2007) allowing us to compare our findings, and because important changes have occurred in the links between the two variables in the mid2000s (see Section 2 and below).
} 
Table 1. Results for the Granger-causality tests between the real oil price and the dollar real effective exchange rate

\begin{tabular}{|c|c|c|}
\hline & real oil price $\rightarrow$ dollar REER & dollar REER $\rightarrow$ real oil price \\
\hline \multicolumn{3}{|c|}{ Whole period from February 1974 to August 2015} \\
\hline$p$-value & 0.1387 & $0.0454^{* *}$ \\
\hline Sign of the relation & Negative & Negative \\
\hline \multicolumn{3}{|c|}{ Previous period from February 1974 to July 2004} \\
\hline$p$-value & 0.5670 & $0.0975^{*}$ \\
\hline Sign of the relation & 0 & Positive \\
\hline
\end{tabular}

Note: $\mathrm{X} \rightarrow \mathrm{Y}$ is for the null hypothesis of no causality from $\mathrm{X}$ to $\mathrm{Y}$. Both variables-the real oil price and the dollar REER-are taken in first-logarithmic differences. ${ }^{* *}$ indicates the rejection of the null hypothesis at the $5 \%$ significance level, ${ }^{*}$ at the $10 \%$ level. Lags are chosen parsimoniously by minimizing the information criteria.

\section{Investigating the nonlinearity of the dollar-oil price nexus}

Given that Figure 1 highlights different evolutions between the oil price and the dollar depending on the fluctuations observed on the forex market, we aim now at investigating this specificity in more detail.

\subsection{Models to be tested}

We rely on the framework of smooth transition regression (STR) models. According to this specification, real oil price changes depend nonlinearly on the real U.S. exchange rate changes, their relationship being dependent on the fluctuations of the U.S. currency. In other words, the observations are divided in two regimes-linear and nonlinear-, with estimated coefficients that vary depending on the considered regime. The change in the estimated value of coefficients is smooth and gradual, since STR models are regime-switching processes in which the transition from one state to the other is smooth rather than discrete. More specifically, our specification is given by:

$p_{t}=\alpha_{0}+\sum_{i=1}^{p} \alpha_{1 i} p_{t-i}+\sum_{j=0}^{q} \alpha_{2 j} e_{t-j}+\left[\beta_{0}+\sum_{i=1}^{p} \beta_{1 i} p_{t-i}+\sum_{j=0}^{q} \beta_{2 j} e_{t-j}\right] F\left(\phi_{t} ; \gamma, c\right)+\varepsilon_{t}$

where $\varepsilon_{t} \sim i i d\left(0, \sigma_{\varepsilon}^{2}\right), p_{t}$ denotes the change in real oil price, $e_{t}$ stands for the dollar REER change (both changes being taken in logarithm), $F\left(\phi_{t} ; \gamma, c\right)$ is the transition function which by convention is bounded by zero and one. $\gamma>0$ denotes the slope parameter that determines 
the smoothness of the transition from one regime to the other (i.e. the abruptness of the transition dynamics at $c$ ), $c$ is the threshold parameter and $\phi_{t}$ is the transition variable.

Inside the framework set by Equation (1), we will successively focus on two models characterized by alternative transition variables. First, it is reasonable to think that the level of the dollar is at stake behind the relationship between the oil price and the dollar rate. Consequently, in Model 1, we take the value of the dollar exchange rate (REER) (in logarithm) as the transition variable (possibly $d$-lagged):

Model 1: $\phi_{t}=\log \left(R E E R_{t-d}\right)$

where $d$ is an integer denoting the delay parameter.

In our second specification and as a robustness check, we retain the $d$-lagged changes of the dollar, $e_{t-d}$, as the transition variable, considering that the dollar change itself could also be a factor influencing the relationship. In other words, the link between our two variables of interest may be different depending on the dynamics, either appreciating or depreciating, followed by the U.S. currency:

Model 2: $\phi_{t}=e_{t-d}$

As regards the transition functions, we retain the two that are commonly considered (Teräsvirta and Anderson, 1992):

$$
\begin{array}{ll}
F\left(\phi_{t} ; \gamma, c\right)=\left(1+\exp \left(-\gamma\left(\phi_{t}-c\right)\right)\right)^{-1} & \text { logistic STR model (LSTR) } \\
F\left(\phi_{t} ; \gamma, c\right)=\left(1+\exp \left(-\gamma\left(\phi_{t}-c_{1}\right)\left(\phi_{t}-c_{2}\right)\right)^{-1}\right. & \text { exponential STR model (ESTR) }
\end{array}
$$

The LSTR specification accounts for asymmetric realizations, in the sense that the two regimes are associated with small and large values of the transition variable relative to the threshold value. In the ESTR model, the range of values between the two estimated thresholds, $c_{1}$ and $c_{2}\left(c_{1}<c_{2}\right)$, obey to a particular dynamics, whereas the values outside this interval respond to another dynamics.

To specify the STR model, we follow the methodology proposed by Teräsvirta (1994). We first test for linearity and, if the null hypothesis is rejected, choose between the LSTR and ESTR specifications using the sequential strategy developed by Teräsvirta (1994). Once this choice has been made, we estimate the STR model and apply various misspecification tests: 
test of no residual autocorrelation (Teräsvirta, 1998), LM-test of no remaining nonlinearity (Eitrheim and Teräsvirta, 1996), and ARCH-LM test (Engle, 1982). ${ }^{6}$

\subsection{Specification tests}

We start by testing the linearity hypothesis using the Fisher-type test proposed in the Teräsvirta (1994)'s procedure. As Equation (1) is not identified under the null hypothesis of linearity, we run the following regression where the transition function $F$ has been replaced by its Taylor development:

$$
p_{t}=\theta_{00}+\theta_{0}^{\prime} z_{t}+\theta_{1}^{\prime} z_{t} \phi_{t}+\theta_{2}^{\prime} \phi_{t}^{2}+\theta_{3}^{\prime} z_{t} \phi_{t}^{3}+\eta_{t}
$$

where $z_{t}^{\prime}=\left(p_{t-1}, \ldots, p_{t-p}, e_{t}, e_{t-1}, \ldots, e_{t-q}\right)$ denotes the vector of our explanatory variables and $\theta_{i}^{\prime}=\left(\theta_{i 11}, \ldots, \theta_{i 1 p}, \theta_{i 20}, \theta_{i 21}, \ldots, \theta_{i 2 q}\right)$, the vector of coefficients associated with $z_{t} e_{t-d}^{i}$ for $i=0$ to 3 . We then test the null hypothesis of linearity as the nullity of the $\theta_{i}$ coefficients for $i=1,2$, 3 - $\left(\mathrm{H}_{0}\right): \theta_{1}=\theta_{2}=\theta_{3}=0$-against its alternative: at least one of the $\theta_{i}$ is different from 0 , for $i=$ 1 to 3 .

As we allow for a lag in the transition variable, we apply the test for different values of the delay parameter $d$-corresponding to different lags —and retain the value of $d$ for which the null hypothesis is the most strongly rejected. The lowest $p$-value is obtained for $d=1$ for Model 1 and $d=2$ for Model 2. As shown in Table 2, the null hypothesis of linearity is rejected at conventional significance levels for the two models (Column (1)).

We then proceed to the choice between the LSTR and ESTR specifications. To do this, we consider the power of the polynomial in Equation (6), as the logistic function can only match an odd degree polynomial and the exponential an even-degree one. We rely on the test sequence provided by Teräsvirta (1994), that proposes to test three null hypotheses sequentially, that we denote $\mathrm{H}_{4}, \mathrm{H}_{3}$ and $\mathrm{H}_{2}$ :

$\left(\mathrm{H}_{4}\right): \theta_{3}=0$

$\left(\mathrm{H}_{3}\right): \theta_{2}=0 / \theta_{3}=0$

$\left(\mathrm{H}_{2}\right): \theta_{1}=0 \mid \theta_{2}=\theta_{3}=0$

\footnotetext{
${ }^{6}$ To save space, we do not report the complete results of misspecification tests, but they are available upon request to the authors. We find that the respective null hypotheses of no error autocorrelation and no remaining nonlinearity are not rejected at conventional significance levels.
} 
If $\mathrm{H}_{4}$ is rejected, the ESTR specification is rejected in favor of the LSTR model. A rejection of $\mathrm{H}_{3}$ indicates an ESTR model. Finally, if $\mathrm{H}_{2}$ is rejected, while $\mathrm{H}_{3}$ is not, the LSTR specification should be retained.

The results of the Fisher tests are reported in Columns (2)-(4) of Table 2 for the two models. In case of Model $1, \mathrm{H}_{4}$ is not rejected in contrast to $\mathrm{H}_{3}$. We thus conclude to an exponential transition function, leading us to retain an ESTR model. Consequently, there are two different regimes depending on the level reached by the U.S. currency: one occurs when the level of the dollar exchange rate remains in its usual middle territories, the other one is triggered when the dollar hits extreme values, either lows or highs.

Turning to Model 2, the results show that only hypothesis $\mathrm{H}_{2}$ can be rejected. Consequently, the LSTR model is the appropriate specification, meaning that there are two regimes involved. The first one prevails when the dollar fluctuations are lower than the estimated threshold, and the second one occurs when the dollar changes exceed the threshold.

Table 2. Results of the specification tests for linearity and the form of the transition function, p-values of the Fisher tests in Equation (6)

\begin{tabular}{cccccc}
\hline & $\mathrm{H}_{0}$ & $\mathrm{H}_{4}$ & $\mathrm{H}_{3}$ & $\mathrm{H}_{2}$ & Conclusion \\
& $(1)$ & $(2)$ & $(3)$ & $(4)$ & \\
\hline Model 1 & $0.0139^{* *}$ & 0.1047 & $0.0184^{* *}$ & 0.2266 & ESTR \\
\hline Model 2 & $0.0051^{* * *}$ & 0.1609 & 0.1046 & $0.0196^{\star *}$ & LSTR
\end{tabular}

Figures represent the $p$-values associated with the Fisher tests on coefficients of Equation (6). ${ }^{* * *}$ (resp. ${ }^{* *}$ ): rejection of the null hypothesis at the $1 \%$ (resp. $5 \%$ ) significance level. The rejection of $\mathrm{H}_{0}$ indicates a nonlinear specification, the rejection of $\mathrm{H}_{2}$ (resp. $\mathrm{H}_{3}$ ) concludes to a logistic (resp. exponential) transition function.

\subsection{Results of the ESTR model}

We now estimate the ESTR model using the level of the dollar (in logarithm) as the transition variable (Model 1). The estimated coefficients are reported on Table 3. According to the estimated thresholds $c_{1}$ and $c_{2}$, the first regime applies as long as the dollar real effective exchange rate remains inside the interval ranging from 93 to 121, the index being based 100 in 1990. Consequently, the second regime occurs when the dollar index either exceeds 121 or slumps below 93. A look at the data displayed on Figure 1 allows us to see that the dollar stays within this $[93,121]$ interval most of the times during the period under review, except mainly through the $1982-1986$ period. 
Table 3. Results of the STR estimation with the USD level (in logarithm) as the transition variable

\begin{tabular}{lccc}
\hline & & Alpha coefficients & Beta coefficients \\
\hline Constant & & 0.0017 & -0.0078 \\
Real oil price & $\mathrm{p}_{\mathrm{t}-1}$ & $0.1884^{* * *}$ & $0.8831^{\star *}$ \\
Dollar REER & $\mathrm{e}_{\mathrm{t}}$ & $-1.0183^{* * *}$ & $0.6828^{* *}$ \\
& $\mathrm{e}_{\mathrm{t}-1}$ & $-0.6802^{* *}$ & $0.8923^{\star}$ \\
\multicolumn{2}{c}{ Sum of lags } & $-1.6985^{\star * *}$ & $1.5751^{* *}$ \\
\hline Slope parameter & $\hat{\gamma}$ & 3.1244 & \\
Threshold values & $\hat{c}_{1}$ & 4.53596 & \\
& $\hat{c}_{2}$ & 4.79451 & \\
\hline
\end{tabular}

Note: The coefficients are obtained by estimating Equation (1) with an exponential transition function. The alpha coefficients refer to the linear part of Equation (1), the beta coefficients, to the nonlinear part that is multiplied by the transition function $F .{ }^{* * *}\left(\right.$ resp. $\left.{ }^{* *},{ }^{*}\right)$ denotes significance at the $1 \%$ (resp. $5 \%$, $10 \%)$ level.

To better understand the size and signs of coefficients, we draw the graph of the transition function relative to the dollar value, over the range of dollar values on our sample (from 90 to 141) (Figure 3). As the slope parameter is low, the transition function is smooth, with very little amplitude over the sample (its value being confined to the interval 0.49 to. 0.55 ).

When calculating the coefficients in function of the dollar level, we see that the simultaneous coefficient is negative, while that with a lag is positive although of smaller magnitude. Overall, the sum of coefficients on the dollar exchange rate change is negative, except for the highest values of the dollar index over 130. As a matter of fact, such high values of the dollar were hit only during the 1984-85 period, following the interest rate hikes in the U.S. By displaying the evolution in coefficients through time, Figure 4 also allows us to check that the impact of the dollar changes on oil price in our ESTR model is negative over the period except for the 1984-1985 years. Aside this particular episode, the STR model confirms the negative relationship detected in the previous section. 
Figure 3. Transition function and size of coefficients on the dollar exchange rate changes in the ESTR model according to the dollar value

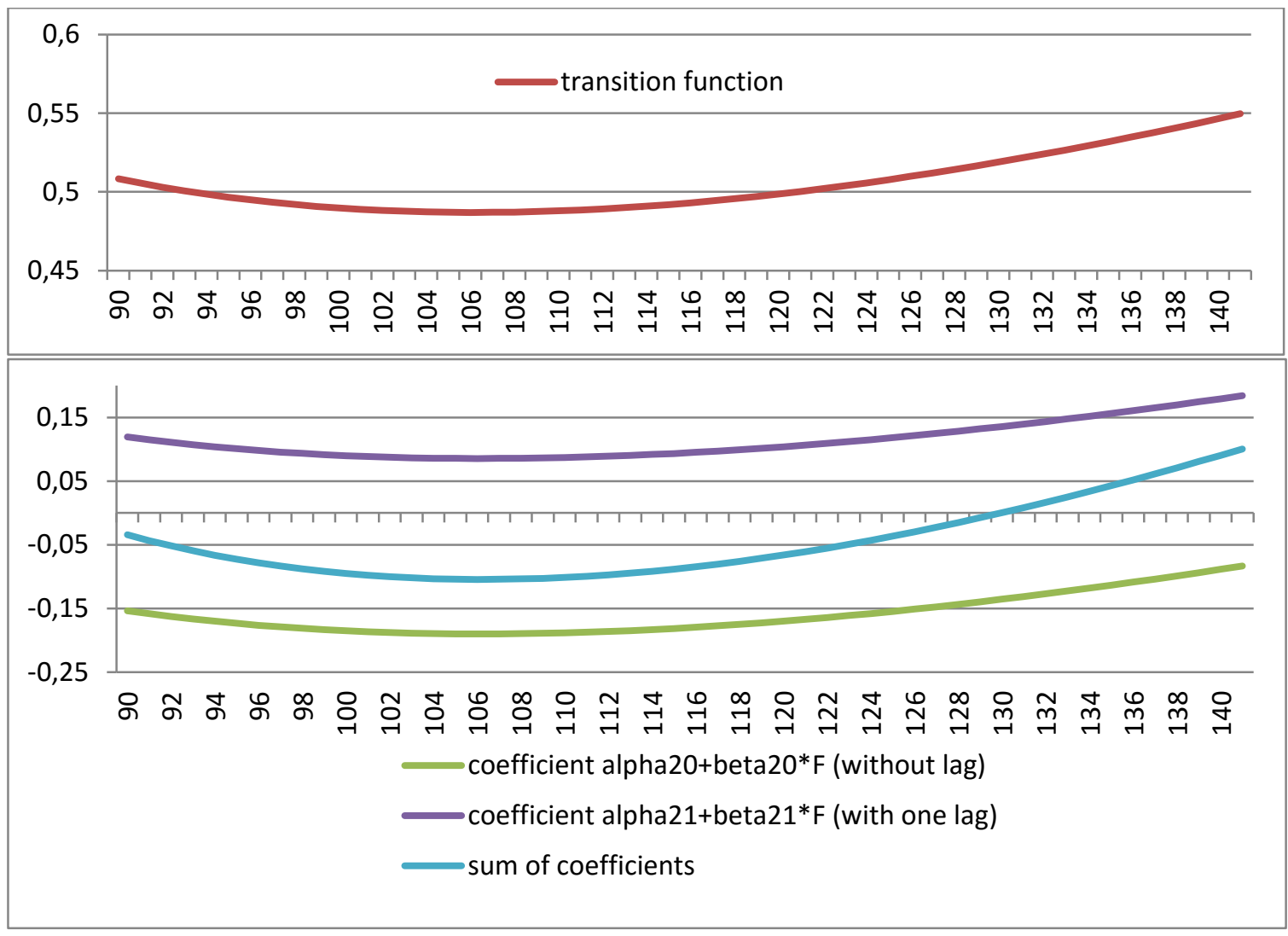

Figure 4. Evolution in the size of coefficients on the dollar exchange rate changes in the ESTR model across time

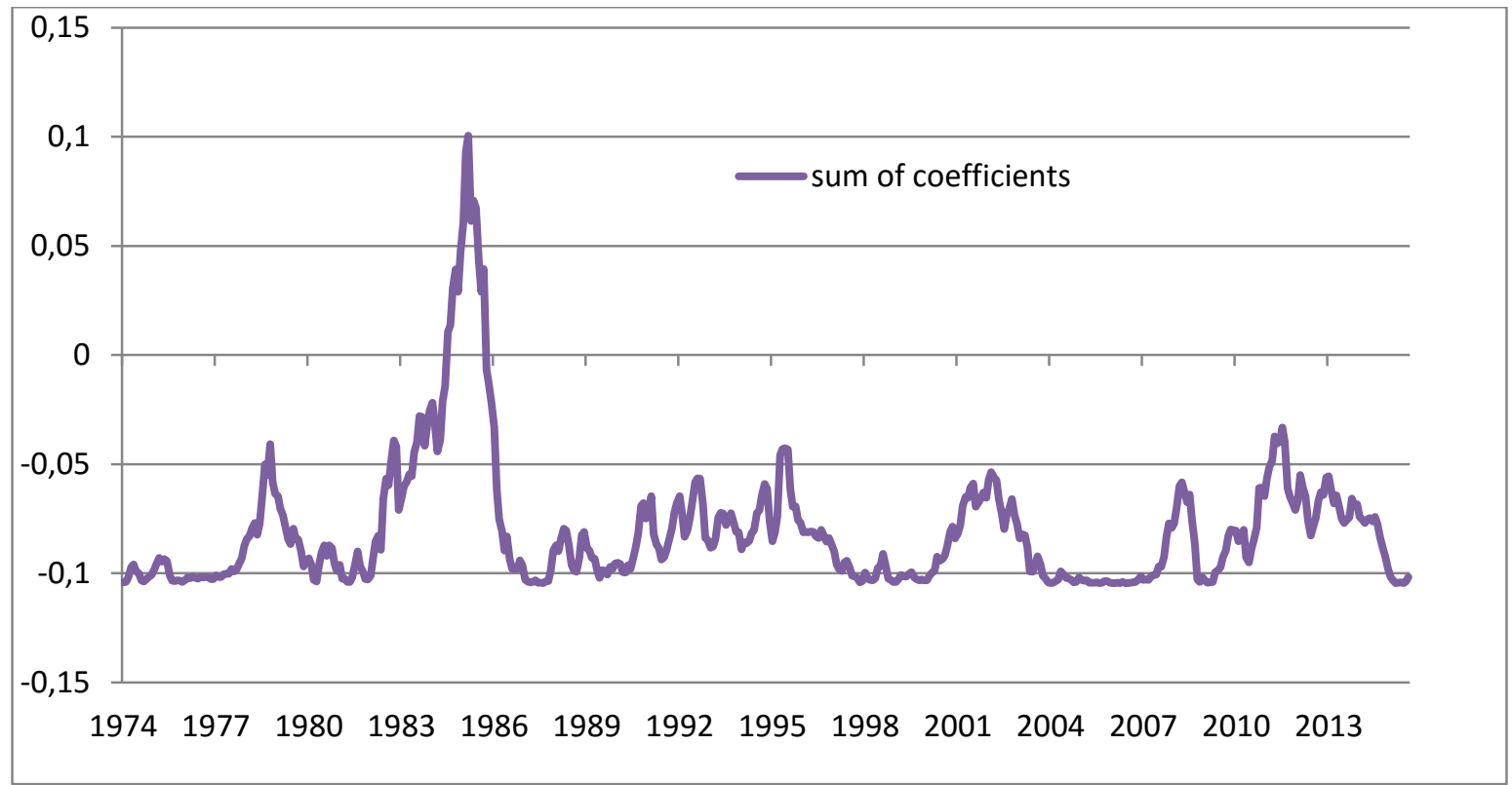


Hence this analysis shows that the high dollar episode in the early eighties distorted the relationship between dollar and oil price changes. This sheds new light on the positive relationship found in former analyses when using shorter series. To understand what is at stake behind this distortion, we have to come back to the theoretical reasons described in Section 2 and explain why they can be modified in this context of high dollar. Obviously, two simultaneous effects must be at stake for inverting the direction between the two variables.

Firstly, the positive channel through petrodollar recycling must have been particularly strong at that time. This can be rationalized by the fact that the mounting dollar far from deterring international investors attracted them all the more, as it is typical in financial bubbles. This episode has to be related to the abnormally high U.S. interest rates in the early eighties, making U.S. assets particularly rewarding. Moreover, there were very few alternative currencies at that time for investing the huge oil surpluses. European currencies were indeed divided and some of them subject to chronical crises, Japan was still protected by tight exchange controls, and emerging countries had no asset to offer in their own currencies.

Secondly, meanwhile, the usual negative channels must have been held up somehow. In particular, the demand adjustment following an oil price hike may have been less effective at that time since the energy substitution process triggered by the first oil shock was still at early stages of progress. Besides, the negative relation going through the equilibrium exchange rate was also inhibited by the "dollar bubble", as the dollar surged well beyond the value consistent with the U.S. fundamentals, leading to a persistent and massive overvaluation (see e.g. Faruquee, 1995; Clark and MacDonald, 1998; Bénassy-Quéré et al., 2004). Turning to the last factor, the financialization of commodities was not already at play in this early period, and then could not foster the negative interactions between the oil price and the dollar.

\subsection{Robustness check: Results of the LSTR model}

As a robustness check and to further investigate the response of the oil price to changes in the USD real effective exchange rate depending on the direction of the dollar fluctuations, we now estimate the second STR model using the dollar changes as the transition variable (Model 2). The estimation results are displayed in Table 4. As shown, the estimated threshold is very close to 0 , as it is equal to $0.482 \%$. This means that the first regimecorresponding to exchange rate variations below $0.5 \%$ a month-roughly refers to a dollar depreciation, and the second one-corresponding to positive exchange rate changes above $0.5 \%$ a month—to a dollar appreciation. 
As the estimated slope parameter is high, the transition between the two regimes is quite rapid, the transition function reaching its maximum value of one as soon as the dollar appreciates by more than $0.5 \%$ and zero otherwise. In this LSTR model, the two regimes are hence easy to grasp: in the first regime, only the alpha coefficients play a role as the transition function is nearly equal to 0 ; in the second regime, the coefficients applied to the dollar changes are equal to the sum of alpha and beta.

Results in Table 4 comfort our previous findings regarding the predominance of a negative link between our two variables of interest over the whole period. Indeed, when the dollar does not appreciate by more than $0.5 \%$ a month, the impact of the U.S. real effective exchange rate on oil price changes is not significant. However, as soon as the dollar appreciates above this threshold, the relation shows a huge negative impact of the dollar changes on oil price variations: during these periods, a $1 \%$ dollar hike triggers a fall in the oil price of approximatively $1.5 \%$, which is the sum of the alpha coefficient $(0.3869)$ and betax $F(-1.9090)$ when $F=1$. This result is highly interesting with regard to the situation observed since the summer 2014 as the price of oil has been declining while dollar strengthened. These findings are in line with our previous estimation results as they highlight that the positive relationship found between both variables in the previous literature is no longer at play when including the recent period.

Table 4. Results of the LSTR estimation with the USD change as the transition variable

\begin{tabular}{lcccc}
\hline & & $\begin{array}{c}\text { Alpha } \\
\text { coefficients } \\
\text { Regime 1 }\end{array}$ & Beta coefficients & $\begin{array}{c}\text { Beta + alpha } \\
\text { coefficients } \\
\text { Regime 2 }\end{array}$ \\
\hline Constant & & 0.0005 & $0.0242^{*}$ & $0.0247^{*}$ \\
Real oil price & $p_{\mathrm{t}-1}$ & $0.3186^{* * *}$ & -0.0627 & 0.2559 \\
& $p_{\mathrm{t}-2}$ & $-0.0983^{*}$ & 0.0477 & -0.0506 \\
Dollar REER & $\mathrm{e}_{\mathrm{t}-1}$ & 0.3869 & $-1.9090^{* * *}$ & $-1.5221^{* * *}$ \\
& $\mathrm{e}_{\mathrm{t}-2}$ & 0.3639 & -1.4780 & -1.1141 \\
\hline Slope parameter & $\hat{\gamma}$ & 19625 & & \\
Threshold value & $\hat{c}$ & 0.00482 & & \\
\hline
\end{tabular}




\section{Conclusion}

In this paper, we have reassessed the empirical linkages between the real price of oil and the U.S. dollar real effective exchange rate. This question is of particular interest given the key role played by both variables at a global level and the massive fluctuations regularly observed on both markets. More specifically, our paper shed light on the post-summer 2014 economic environment as the plummet in the oil price has been accompanied by a sharp appreciation of the U.S. dollar since that time.

We show that previous findings of the literature highlighting a positive link between both variables are called into question when updating data to include the recent period. Working over the 1974-2015 period, we find evidence of a short-run relationship going from the dollar real exchange rate to the oil price variations. We show that this relationship is negative over the whole period, although it is found positive when considering the subsample ending in the mid-2000s.

Given such fluctuations in the direction of the relationship across time, we investigate the possible nonlinear effects, relying on the smooth transition regression model framework. The estimation results allow us to show that the dollar changes have negative impact on the oil price most of the times, except when the dollar reaches particularly high levels. During these episodes of high dollar values, the relation between both variables turns positive. Over our sample, this situation occurred only in the early eighties, when abnormally high interest rates in the U.S. pushed up the dollar exchange rate. At that time, the surging oil price led oilexporters to recycle their surpluses in purchasing the highly rewarding dollar assets, contributing to the dollar hike and the positive relationship - this effect being accentuated by the lack of alternative currencies to invest in at this period. Moreover, as the U.S. foreign assets declined after the surge in the oil price, the normal adjustment, that should have brought about a dollar drop, was inhibited by the oddly high interest rates, encumbering the normal negative relationship between our two variables of interest.

To interpret the negative link prevailing nowadays, we have to take into account the fact that oil and commodity markets have become more and more financialized for the last decade. As investors and asset managers regularly arbitrage across financial and commodity markets, they are likely to find commodities less attractive, when the dollar is expected to go upward. Meanwhile, the diversification of OPEC's portfolios specifically through sovereign wealth funds has wiped off the positive relationship that used to link oil price to the dollar through petrodollar recycling. 


\section{References}

Amano, R. and van Norden, S. (1995), Exchange rates and oil prices, Bank of Canada, Working Paper.

Becker, R., Clements, A. and McClelland, A. (2009), The Jump Component of S\&P 500 Volatility and the VIX Index, Journal of Banking and Finance 33(6), 1033-1038.

Bénassy-Quéré, A., Duran-Vigneron, P., Larèche-Révil, A. and Mignon, V. (2004), Burden Sharing and Exchange Rate Misalignments within the Group of Twenty, in C. Fred Bergsten and John Williamson (eds), Dollar Adjustment: How Far? Against What?, Institute for International Economics Special Report 17.

Bénassy-Quéré, A., Mignon, V. and Penot, A. (2007), China and the relationship between the oil price and the dollar, Energy Policy 35, 5795-5805.

Clark, P. and MacDonald, R. (1998), Exchange rates and economic fundamentals: a methodological comparison of BEERs and FEERs, International Monetary Fund Working Paper 98/00.

Cline, R. (2011), Estimates of Fundamental Equilibrium Exchange Rates in May 2011, Policy Brief 11-5, Peterson Institute for International Economics.

Coudert, V., Couharde, C. and Mignon, V. (2011), Does Euro or Dollar Pegging Impact the Real Exchange Rate? The Case of Oil and Commodity Currencies, World Economy 34(9), 1557-1592.

Coudert, V., Mignon, V. and Penot, A. (2007), Oil price and the dollar, Energy Studies Review 15(2), 1-18.

Dibooglu, S. (1995), Real disturbances, relative prices, and purchasing power parity, Southern Journal of Economics.

Domanski, D. and Heath, A. (2007), Financial investors and commodity markets, BIS Quarterly Review, March, 53-67.

Eitrheim, O. and Teräsvirta, T. (1996), Testing the Adequacy of Smooth Transition Autoregressive Models, Journal of Econometrics 74, 59-76.

Engle, R.F. (1982), Autoregressive Conditional Heteroscedasticity with Estimates of the Variance of United Kingdom Inflation, Econometrica 50(4), 987-1007. 
Faruqee, H (1995), Long-run determinants of the real exchange rate - A stock-flow perspective, IMF Staff papers, Vol. 42, 855-881, March.

Fratzscher, M., Schneider, D. and Van Robays, I. (2014), Oil Prices, Exchange Rates and Asset Prices, European Central Bank Working Paper N¹689, July.

Geman, H. and Kharoubi, C. (2008), WTI crude oil Futures in portfolio diversification: The time-to-maturity effect, Journal of Banking \& Finance 32, 2553-2559.

Gorton, G. and Rouwenhorst, K.G. (2006), Facts and Fantasies about Commodity Futures, Financial Analysts Journal 62(2), 47-68.

Greely, D. and Currie, J. (2008), Speculators, Index Investors and Commodity Prices, Global Economic Paper, Goldman Sachs, June 29.

Golub, S. (1983), Oil prices and exchange rates, The Economic Journal 93 (371), 576-593.

Johansen, S. (1988), Statistical analysis of co-integration vectors, Journal of Economic Dynamics and Control 12, 231-254.

Kat, H.M. and Oomen, R.C.A. (2006), What Every Investor Should Know About Commodities, Part I: Univariate Return Analysis, Cass Business School Research Paper, January.

Krugman, P. (1983a), Oil and the dollar in Bhandari, J. and Putnam, B. (eds), Economic interdependence and flexible exchange rates, MIT Press.

Krugman, P. (1983b), Oil shocks and exchange rate dynamics in Frankel, J.A. (ed), Exchange rates and international macroeconomics, University of Chicago Press.

Mayer, J. (2009), The Growing Interdependence between Financial and Commodity Markets, United Nations Commission on Trade and Development, Discussion Paper No. 195, October.

Teräsvirta, T. (1994), Specification, Estimation, and Evaluation of Smooth Transition Autoregressive Models, Journal of the American Statistical Association 89, 208-218.

Teräsvirta, T. (1998), Modeling economic relationships with smooth transition regressions, in A. Ullah and D. Giles (eds), Handbook of Applied Economic Statistics, Dekker, New York, 229-246. 
Teräsvirta, T. and H.M. Anderson (1992), Characterizing Nonlinearities in Business Cycles Using Smooth Transition Autoregressive Models, Journal of Applied Econometrics 7(S), S119-36.

Throop, A. (1993), A generalized uncovered interest parity model of exchange rates, Federal Reserve Bank of San Francisco Economic Review 2, 3-16.

Zhou, S. (1995), The response of real exchange rates to various economic shocks, Southern Journal of Economics, 936-954. 


\section{Appendix}

Figure A1. Generalized impulse-response functions for the trivariate VAR

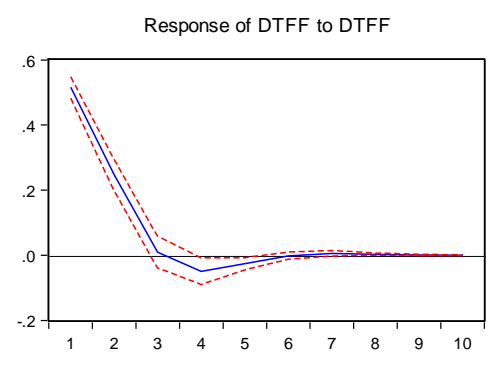

Response to Generalized One S.D. Innovations \pm 2 S.E.
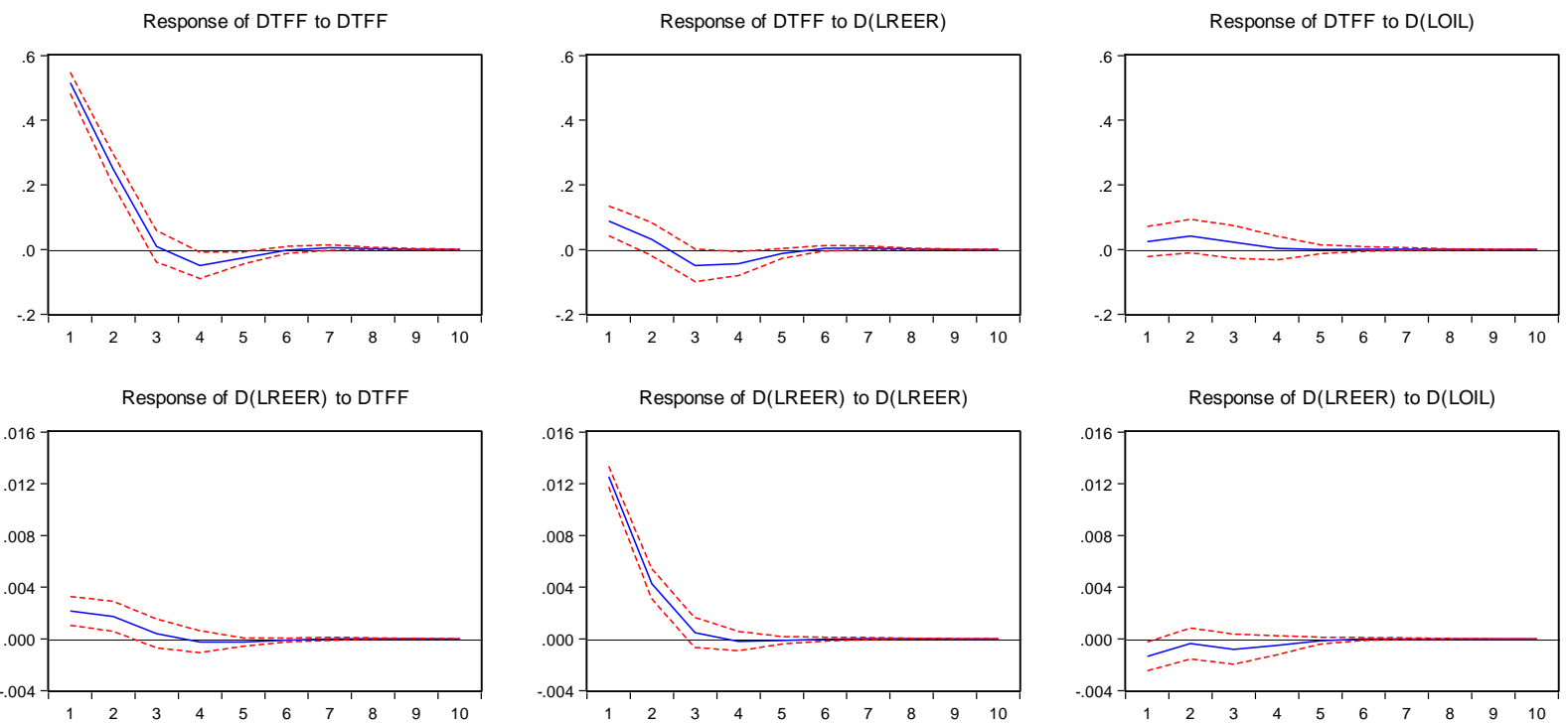

Response of $\mathrm{D}(\mathrm{LOIL})$ to DTFF
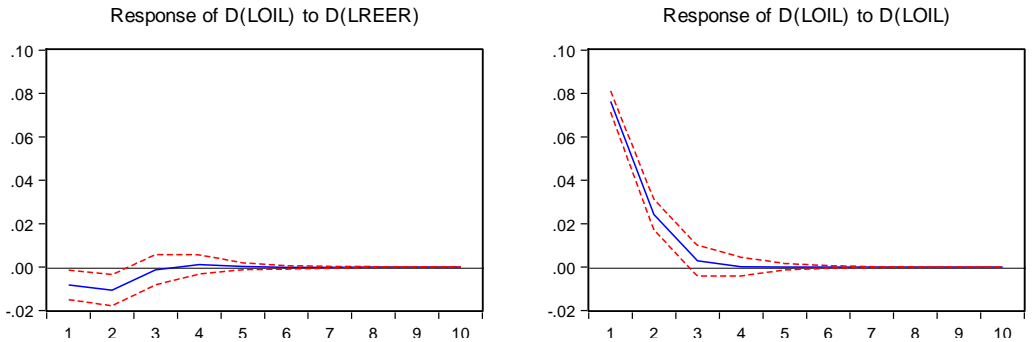

Note: the generalized impulse-response functions correspond to the estimation of a trivariate $\operatorname{VAR}(2)$ process in first differences. TFF denotes the Fed funds rate. The lag of the VAR process has been selected using information criteria. 